\title{
How are Probiotics Affected by Antibiotics?
}

\author{
Heidi L Rowles \\ Biological Sciences/Food and Nutrition Major, Clermont College, University of Cincinnati, Goshen, USA
}

Corresponding author: Heidi L Rowles, Biological Sciences/Food and Nutrition Major, Clermont College, University of Cincinnati, Goshen, USA, Tel: 5136462599; E-mail: rowleshl@mail.uc.edu

Received: 20 March 2017; Accepted: 15 April 2017; Published: 20 April 2017

Citation: Rowles HL. How are Probiotics Affected by Antibiotics? Ann Clin Lab Res. 2017, 5: 2.

\section{Abstract}

Probiotics are commercial products that contain healthy bacteria normally found in the gut flora. Each person has billions of bacteria living in their gut. Antibiotics are medications commonly prescribed for infections caused by pathogenic bacteria. Each antibiotic function in a unique way to rid the body of a specific type of bacteria; however, gut bacteria are inadvertently destroyed by antibiotics. The initial step of this project was to test a number of probiotic products to confirm their ability to grow in a medium which will verify that these products do indeed deliver viable gut bacteria to the person ingesting them. Probiotic products are available that contain single strains of bacteria as well as up to thirty different strains in one product. This allows for testing of a cross-section of the gut bacteria which are represented by the bacteria in the probiotics. The second focus of my project was to treat gut bacteria grown on a medium with different antibiotics to test whether any or all of the gut bacteria are in fact destroyed by antibiotics. The human body is host to a vast array of healthy bacteria in the gut. Using an assortment of antibiotics on each probiotic plate offers the opportunity to compare the devastation caused by each antibiotic on the various gut bacteria made available by the probiotics.

Keywords: Probiotics; Antibiotics; Gut bacteria; Dysbiosis; Resistant bacteria; Zone of inhibition; Antibiotic disc

\section{Introduction}

Probiotic is a Greek word that means "for life" [1]. The meaning of the word probiotic has changed often over the years but might be best described as "a preparation of viable microorganisms which is consumed by humans and other animals with the aim of inducing beneficial effects by quantitatively or qualitatively influencing their gut flora and/or modifying their immune status" [2]. The first objective of this project was to test a number of probiotic products to confirm their ability to grow in a medium which verified that these products do indeed deliver viable bacteria to the person ingesting them.
Following the discovery and commercialization of antibiotics, studies have investigated the effects of antibiotics on indigenous gut microbes [3]. By the year 1950, antibiotics had become the preferred treatment for a multitude of diagnoses ranging from infections to tuberculosis [4]. However, antibiotic treatment can alter the composition or the function of the intestinal gut flora which results in overgrowth of pathogenic, toxigenic and antibiotic-resistant bacteria and reduction or possibly even complete loss of beneficial bacterial strains [5]. Antibiotics can kill the good bacteria in the gut, leaving the body more susceptible to harmful pathogens [6].

Antibiotics are indiscriminant in eradicating bacteria and thus can have a deleterious effect on the healthy bacteria in a person's body as the antibiotic works to eliminate the pathogenic bacteria. This change in a person's gut flora due to antibiotics creates an imbalance of the bacteria: the condition is called dysbiosis. Administering a probiotic concurrently with an antibiotic can reduce the risk of dysbiosis as well as other antibiotic-related problems associated with the gut bacteria such as inflammation, yeast overgrowth, diarrhea and super infections [6]. Taking probiotics during antibiotic treatment may help to maintain healthy gut microbes and restore the flora to a homeostatic environment where the beneficial microbes help fight off pathogenic bacteria [5]. The second objective of this project was to examine the effect of several antibiotics on probiotics. I hypothesized that every antibiotic chosen would have an effect, or a measurable zone of inhibition, on each probiotic plate.

The specific bacteria contained in probiotics function as a sample of the bacteria living in the human gut. No study has been published yet that shows the direct effect of antibiotics on probiotics. As the number of probiotics prescribed concurrently with antibiotics increases along with the overall market for probiotics, it is important to study the interaction of these two products and what the outcome may be for the individual taking them.

\section{Materials and Methods}

\section{Bacterial strains and growth conditions}

The probiotics chosen were from a variety of price ranges from $\$ 10$ to $\$ 60$ a bottle. Each probiotic used in this study contained a different combination of bacteria (see Appendix A); some required refrigeration and some did not. Most were 
in capsule form and two were beverages. Each probiotic was added to a test tube containing $10 \mathrm{~mL}$ of tryptic soy broth (TSB) (manufactured by Carolina Biological Supply Company, Burlington, NC, USA): $1.0 \mathrm{~mL}$ of the liquid probiotics and $0.05 \mathrm{~g}$ of each of the tablet or capsule brands were used (Table 1). These solutions were mixed with a vortex until the probiotic was completely dissolved in the broth; they were then incubated for 36 hours at $37^{\circ} \mathrm{C}$ to allow the bacteria to grow. The cultured probiotics were spread on tryptic soy agar (TSA) plates (manufactured by Carolina Biological Supply Company, Burlington, NC, USA) and incubated for 48 hours. The number of colony forming units or CFU used for each probiotic as well as the concentration density of probiotic bacteria on each plate (shown as CFU/ $\mathrm{cm}^{2}$ ) is shown in Table 1.

Table 1 The brand of probiotic and the amount incubated in broth (see Appendix A for the specific genus and species included in each band of probiotic).

\begin{tabular}{|c|c|c|c|c|}
\hline Plate Number & Probiotic Brand & Amount used & $\begin{array}{l}\text { CFU in } 1.0 \mathrm{~mL} \\
\text { solution }\end{array}$ & $\begin{array}{l}\text { Density of Probiotic on plate } \\
\left(\mathrm{CFU} / \mathrm{cm}^{2}\right)\end{array}$ \\
\hline 1 & Garden of Life RAW Probiotics for Women & $0.05 \mathrm{~g}$ & $7.08 \times 10^{8}$ & $1.25 \times 10^{7}$ \\
\hline 2 & Good Belly & $1.0 \mathrm{~mL}$ & $2.5 \times 10^{7}$ & $4.41 \times 10^{5}$ \\
\hline 3 & Kefir & $1.0 \mathrm{~mL}$ & $4.2 \times 10^{6}$ & $7.40 \times 10^{4}$ \\
\hline 4 & Nature's Bounty Probiotic GX & $0.05 \mathrm{~g}$ & $1.89 \times 10^{8}$ & $3.33 \times 10^{6}$ \\
\hline 5 & Nature's Bounty Controlled Delivery & $0.05 \mathrm{~g}$ & $1.47 \times 10^{7}$ & $2.59 \times 10^{5}$ \\
\hline 6 & Sundown Naturals Probiotic Balance & $0.05 \mathrm{~g}$ & $1.25 \times 10^{8}$ & $2.20 \times 10^{6}$ \\
\hline 7 & Nature's Bounty Probiotic 10 & $0.05 \mathrm{~g}$ & $3.13 \times 10^{7}$ & $5.52 \times 10^{6}$ \\
\hline 8 & Ultimate Flora & $0.05 \mathrm{~g}$ & $3.41 \times 10^{8}$ & $6.01 \times 10^{6}$ \\
\hline 9 & Kroger Acidophilus & $0.05 \mathrm{~g}$ & $1.0 \times 10^{8}$ & $1.76 \times 10^{6}$ \\
\hline
\end{tabular}

\section{Antibiotics used}

The probiotics chosen for this project are all Gram-positive bacteria. Each of the antibiotics chosen is either used to treat only Gram-positive or both Gram-positive and Gram-negative bacteria (Table 2). Gram-positive and Gram-negative are ways that bacteria are classified based on their cell wall structure.
Gram-positive bacteria have a thin cell wall composed of a coating of peptidoglycan over the cell membrane. Gramnegative bacteria have a thick cell wall that is comprised of a thin layer of peptidoglycan in between two layers of cell membrane [7]. Gram-positive and Gram-negative bacteria are treated with different types of antibiotics that affect the components of the outer layer of the cell wall.

Table 2 Antibiotics used, their function and treatment spectrum.

\begin{tabular}{|l|l|l|}
\hline Antibiotic & Function & Spectrum \\
\hline Sulfanilamide & block folic acid synthesis & Gram-positive and Gram-negative \\
\hline Ampicillin & inhibit cell wall synthesis & Gram-positive and Gram-negative \\
\hline Tetracycline & inhibit protein synthesis & Gram-positive and Gram-negative \\
\hline Oxacillin & inhibit cell wall synthesis & Gram-positive \\
\hline Vancomycin & inhibit cell wall synthesis & Gram-positive and Gram-negative \\
\hline
\end{tabular}

\section{Synthesis of sulfanilamide}

The synthesis of sulfanilamide was performed according to the procedure described by Williamson [8].

The initial compound, $0.25 \mathrm{~g}$ of acetanilide, was measured into a $25 \mathrm{~mL}$ Erlenmeyer flask. The flask was fitted with a septum that had been connected to a short length of polyethylene tubing leading into a reaction tube that contained a small piece of damp cotton to trap $\mathrm{HCl}$ vapors. A few drops at a time, $0.625 \mathrm{~mL}$ of $\mathrm{ClHO}_{3} \mathrm{~S}$ was added from a capped vial using a Pasteur pipette. In between additions of the $\mathrm{ClHO}_{3} \mathrm{~S}$, the flask was connected to the gas trap. The reaction subsided in about 10 minutes and only a few small pieces of $\mathrm{C}_{8} \mathrm{H}_{9} \mathrm{NO}$ remained undissolved. The mixture was heated on a steam bath for 10 minutes to complete the reaction and then the flask was cooled on ice. The oily product was added by drop into $3.5 \mathrm{~mL}$ of ice water contained in a 10 $\mathrm{mL}$ Erlenmeyer flask; the ice water was stirred while the product was added. The flask was rinsed with cold water and the precipitated $\mathrm{C}_{8} \mathrm{H}_{8} \mathrm{ClNO}_{3} \mathrm{~S}$ was stirred for a few minutes until an even suspension of granular white solid (filter cake) was obtained. The precipitate was collected using vacuum filtration. The filter cake was pressed and drained. The solid was transferred to the rinsed reaction flask, and then $0.75 \mathrm{~mL}$ 
of concentrated aqueous $\mathrm{NH}_{4} \mathrm{OH}$ and $0.75 \mathrm{~mL}$ of water were added to the flask. The mixture was heated and swirled over a hot sand bath for five minutes, with the temperature kept just below boiling. A change was noted as the sulfonyl chloride underwent transformation to a more pasty suspension of the amide. The suspension was cooled in an ice bath and the $\mathrm{C}_{8} \mathrm{H}_{10} \mathrm{~N}_{2} \mathrm{O}_{3} \mathrm{~S}$ was collected by vacuum filtration. The cake on the Hirsch funnel was pressed and allowed to drain thoroughly to remove any excess water that would unduly dilute the acid used in the next step. The still-moist amide was transferred to the well-drained reaction flask and $0.25 \mathrm{~mL}$ of concentrated $\mathrm{HCl}$ and $0.5 \mathrm{~mL}$ of water were added. The mixture was boiled gently until the solid had all dissolved and then was heated for 10 more minutes. The product obtained was the solution of sulfanilamide to be used to treat the probiotics.

\section{Treating probiotic plates with antibiotics}

The following protocol was adopted from Fankhauser [9].

Thirty-six pre-treated antibiotic discs were used to treat the lawn (plate) of probiotics. Four sets of nine discs each, obtained from the biology lab, contained the following concentrations of antibiotics: oxacillin $1 \mu \mathrm{g}$, ampicillin $10 \mu \mathrm{g}$, vancomycin $30 \mu \mathrm{g}$, and tetracycline $30 \mu \mathrm{g}$. These antibiotics were chosen because they are all common antibiotics used to treat Gram-positive bacteria and were available in the lab. The antibiotic discs were manufactured by BD BBL Sensi-Disc Susceptibility Test Disc, Becton, Dickinson \& Company, Sparks, MD, USA.

A schematic was drawn of all plates to be used and labeled (Figure 1). To prepare the plate, the contents of each test tube containing a probiotic and TSB were mixed using a vortex. A probiotic culture of $1.0 \mathrm{~mL}$ was pipetted onto an agar plate. A spreader was sterilized with alcohol and heated over the flame of a Bunsen burner. Then the probiotic was evenly spread across the entire surface of the agar using a turntable. The plate sat undisturbed for several minutes so that the bacteria could dry and then the antibiotic discs were applied. One blank disc was placed in the center of each plate and was inoculated with $10 \mu \mathrm{L}$ of the sulfanilamide solution that was synthesized. Using a pipette, the sulfanilamide was added slowly, allowing the liquid to be absorbed into the disc. Following the schematic, the pre-treated discs were applied to each plate carefully with sterilized tweezers. The plates were inverted and incubated at $37^{\circ} \mathrm{C}$ for 48 hours. The plates were removed from the incubator and the zones of inhibition around each disc were measured in centimeters.

\section{Results}

In the initial part of this project, the probiotics grew cultures, indicating that all of the probiotics contain live bacteria. Figure 1 shows Petri dishes filled with agar that has been coated with a probiotic and treated with five antibiotic discs. If the antibiotic was effective, a zone of inhibition was observed where the bacteria did not grow.

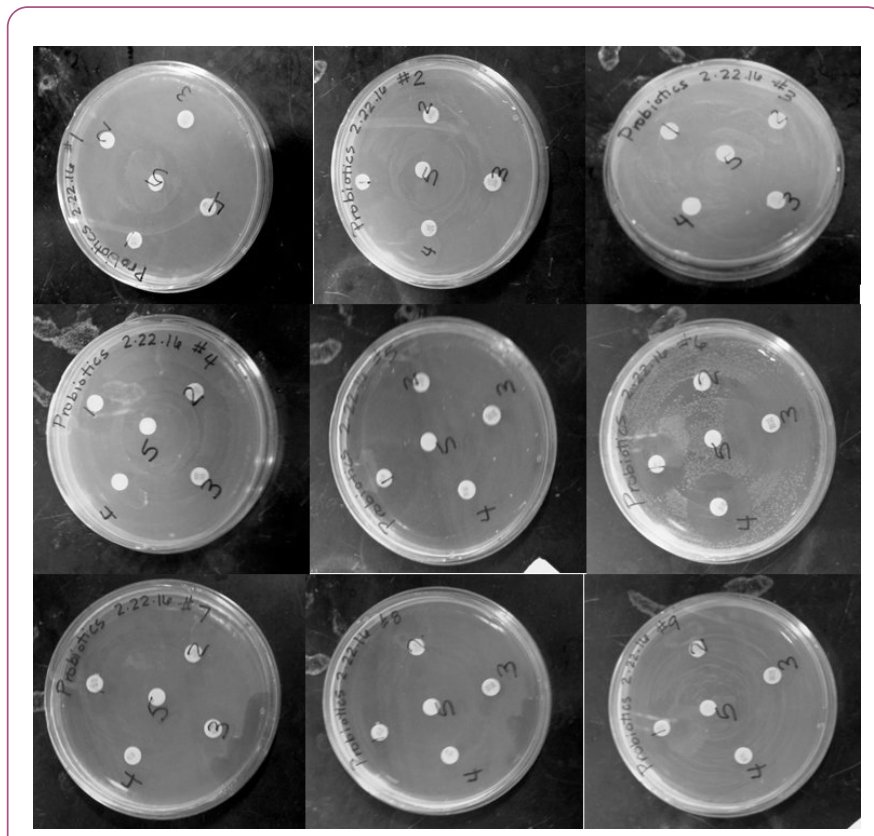

Figure 1 The antibiotics' activity with different probiotics.

The measurements for each zone of inhibition are shown in Table 3. The ampicillin showed effective against all of the probiotics with zones of inhibition measuring $2.0 \mathrm{~cm}$ to $3.0 \mathrm{~cm}$. The tetracycline showed effective against all of the probiotics except \#1 and its zones of inhibition measured $0.9 \mathrm{~cm}$ to 3.3 $\mathrm{cm}$. The sulfanilamide only showed effective against \#1 with $2.2 \mathrm{~cm}$ and \#2 with $3.0 \mathrm{~cm}$. Vancomycin showed effective against \#6 with a $2.6 \mathrm{~cm}$ zone of inhibition and oxacillin showed effective against \#5 with a $1.5 \mathrm{~cm}$ zone of inhibition.

Table 3 The measurement of zones of inhibition of each plate, \#1-\#9 (Table 1), measured in cm.

\begin{tabular}{|c|c|c|c|c|c|c|c|c|c|}
\hline & \#1 & \#2 & \#3 & \#4 & \#5 & \#6 & \#7 & \#8 & \#9 \\
\hline Ampicillin & 2.5 & 2.5 & 3.0 & 2.0 & 3.0 & 2.3 & 2.4 & 2.4 & 2.5 \\
\hline Tetracycline & 0.0 & 1.2 & 3.0 & 1.5 & 1.5 & 3.3 & 1.7 & 0.9 & 1.1 \\
\hline Sulfanilamide & 3.0 & 2.2 & 0.0 & 0.0 & 0.0 & 0.0 & 0.0 & 0.0 & 0.0 \\
\hline Vancomycin & 0.0 & 0.0 & 0.0 & 0.0 & 0.0 & 2.6 & 0.0 & 0.0 & 0.0 \\
\hline Oxacillin & 0.0 & 0.0 & 0.0 & 0.0 & 1.5 & 0.0 & 0.0 & 0.0 & 0.0 \\
\hline
\end{tabular}




\section{Discussion}

A variety of probiotic products were tested to determine if they contained live cultures. All of the probiotics grew cultures, indicating that each of the products chosen do, in fact, contain live cultures that will deliver viable healthy bacteria when consumed. The probiotics were all viable and could be used for the project.

It was expected that all of the antibiotic discs would have been effective against each of the probiotics used. A measurable zone of inhibition around an antibiotic disc in this type of project shows that the antibiotic would be effective at killing those particular bacteria. Each antibiotic disc should have had a measurable zone of inhibition around it on each plate; however, each probiotic was only inhibited by two or three antibiotics. A variety of antibiotics were chosen for this initial experiment to determine which gram-positive bacteria may have an effect on the probiotic bacteria. Sulfanilamide was chosen because due to increased antibiotic resistance, antibiotics that have been mostly discontinued in clinical use are being investigated as possible treatments if resistance is not as strong to these antibiotics.

The lack of effectiveness of the antibiotic discs could be indicative of several factors. The concentration of the probiotic bacteria may not have been the ideal concentration for the concentration of antibiotic used. The probiotic bacteria could be resistant to antibiotics. Antibiotic resistance has been found in probiotic bacteria and could provide an explanation as to why all of the probiotics did not show zones of inhibition around each antibiotic disc. Significant zones around some of the discs suggest that there could be other reasons that all of the antibiotics did not show effectiveness against the bacteria on each plate (Figure 2).

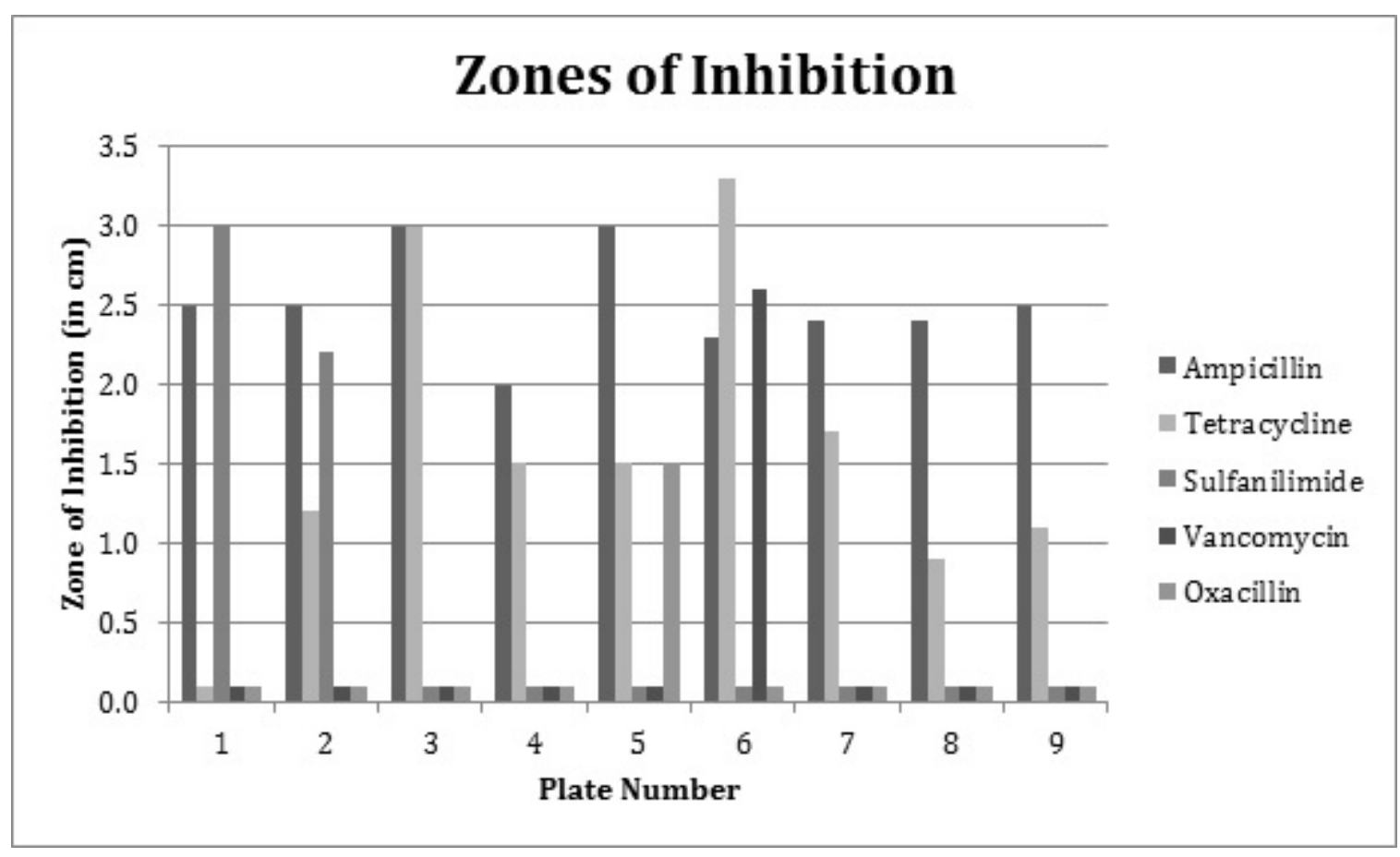

Figure 2 Measurement of zones of inhibition around each antibiotic disc on probiotic plates 1-9.

Bacterial resistance is a growing problem; gut bacteria as well as probiotics are susceptible to developing antibiotic resistance [10]. A study done by Han showed that probiotics on the market contain bacterial resistance [11]. Another study showed that gut bacteria have resistance and because the bacteria in the gut are exposed to other bacteria that pass through the digestive tract, they are able to share this resistance [10]. It is possible that some of the probiotics used for this project possess antibiotic resistance and this is why they did not respond to the antibiotics. Another explanation for the inconsistent results could be caused by not using the correct dosage or concentration of the individual antibiotic for the amount of bacteria on the plate. A study done by Lin et al. [12] testing the effect of five antibiotics on the gut bacteria of Plutella xylostella larva showed that the antibiotics tested had positive results of damaging effects on the gut bacteria at varying dosages.

If a probiotic contains bacterial strains that exhibit antibiotic resistance, this resistance could be spread to the bacteria that is being treated and cause the pathogenic bacteria to become resistant [10]. Bacteria are capable of sharing resistance and this is how multiple-resistant bacteria have been formed. By introducing healthy bacteria into a person's gut that contain antibiotic resistance, multiple resistant pathogenic bacteria could be created in an environment that hosts trillions of bacterial cells. Bacteria are found everywhere, even in hospitals and healthcare facilities where patients have compromised immune systems. Creating more strains of multiple-resistant bacteria in these facilities could have deleterious effects on the patients staying there [13]. 
Antibiotics decrease the amount of healthy bacteria in a person's gut flora. A course of probiotics can help to restore the gut flora to a healthy state. I propose that taking probiotics concurrently with antibiotics may help reduce a person's risk of developing antibiotic-related dysbiosis.

Antibiotics are classified by their mechanism for eradicating bacteria; different antibiotics are used to treat different types of bacteria and will therefore have varying effects on the gut bacteria and any probiotics taken concurrently. Further study needs to be performed to establish conclusive results of the effect of each antibiotic on the probiotics. I am currently investigating the effect of several antibiotics on a specific range of concentrations of probiotics to determine possible relationships between antibiotic dosage and bacterial concentration. As part of the ongoing investigation, concentrations of probiotics and antibiotics should be tested in proportion to what is present in the normal gut to determine possible baseline of detriment to the microbiome by antibiotics. The antibiotics chosen for this study were done so to begin an investigation into the reactivity of probiotic bacteria to the antibiotics. Regardless of the route of administration of an antibiotic, the antibiotic will have an effect on the gut bacteria. Further investigation into each antibiotic will be important in the future to establish a relationship between antibiotics and probiotic bacteria as a way to preserve digestive health in the event of antibiotic consumption.

\section{Acknowledgements}

I would like to acknowledge Dr. Bozena Widanski, Dr. JoAnn Thompson, Fannie Courtier, Nick Maiorano, Meldrick Mpagi and Dr. Daniel Carson for their knowledge, support and encouragement.

\section{References}

1. London RF (1993) Probiotics: The Scientific Base. Complement Ther Med 1: 111.
2. Fuller $\mathrm{R}$ (2006) Reasons for the apparent variation in the probiotic response. Biologia 61: 751-754.

3. Modi SR, Collins JJ, Relman DA (2014) Antibiotics and the gut microbiota. J Clin Invest 124: 4212-4218.

4. Liebenau J (1982) Review of the history of antibiotics: A symposium. Isis 73: 148.

5. Macfarlane S (2014) Antibiotic treatments and microbes in the gut. Environ Microbiol 16: 919-924.

6. Boyanova L, Mitov I (2012) Coadministration of probiotics with antibiotics: Why, when and for how long? Expert Rev Anti Infect Ther 10: 407-409.

7. Todar K (2014) Structure and function of bacterial cells. In: Todar K (Ed.), Todar's Online Textbook of Bacteriology (1stedn.) p. 5. Retrieved from http://www.wsmicrobiology.com/todars-onlinetextbook-bacteriology/

8. Williamson KL, Masters K (1989) Macroscale and microscale organic experiments (6thedn.). Lexington, MA: D.C. Heath.

9. Fankhauser D (2013) Microbiology lab manual. Batavia, OH: University of Cincinnati Clermont College.

10. Wong A, Ngu DY, Dan LA, Ooi A, Lim RL (2015) Detection of antibiotic resistance in probiotics of dietary supplements. Nutr J 14: 95.

11. Han J, Chen D, Li S, Li X, Zhou W, et al. (2015) Antibiotic susceptibility of potentially probiotic lactobacillus strains. Ital J Food Sci 27: 282-289.

12. Lin X, Kang Z, Pan Q, Liu T (2014) Evaluation of five antibiotics on larval gut bacterial diversity of Plutella xylostella (Lepidoptera: Plutellidae). Insect Sci 22: 619-628.

13. Basu S (2014) Neonatal sepsis: The gut connection. Eur J Clin Microbiol Infect Dis 34: 215-222. 